\title{
Article
}

\section{Antihyperuricemic, Anti-Inflammatory and Antihypertensive Effect of a Dry Extract from Solidago virgaurea L. (Asteraceae)}

\author{
Mircea Tămaş ${ }^{1}$, Oliviu Vostinaru ${ }^{2, *}{ }^{\circledR}$, Loredana Soran ${ }^{3}$, Ildiko Lung ${ }^{3}$, Ocsana Opris ${ }^{3}$, Anca Toiu ${ }^{4}(\mathbb{D}$, \\ Alexandru Gavan ${ }^{5}$, Elena Dinte ${ }^{5}$ and Cristina Mogosan ${ }^{2} \mathbb{D}$ \\ 1 Department of Pharmaceutical Botany, Iuliu Hatieganu University of Medicine and Pharmacy, 23 Gh. \\ Marinescu, 400337 Cluj-Napoca, Romania; mtbotanica@yahoo.com \\ 2 Department of Pharmacology, Physiology, Physiopathology, Iuliu Hatieganu University of Medicine and \\ Pharmacy, 6A L. Pasteur, 400349 Cluj-Napoca, Romania; cmogosan@umfcluj.ro \\ 3 National Institute for Research and Development of Isotopic and Molecular Technologies, 67-103 Donath, \\ 400293 Cluj-Napoca, Romania; loredana_soran@yahoo.com (L.S.); ildiko.lung@itim-cj.ro (I.L.); \\ ocsana.opris@itim-cj.ro (O.O.) \\ 4 Department of Pharmacognosy, Iuliu Hatieganu University of Medicine and Pharmacy, 12 I. Creanga, \\ 400010 Cluj-Napoca, Romania; ancamaria_toiu@yahoo.com \\ 5 Department of Pharmaceutical Technology and Biopharmaceutics, Iuliu Hatieganu University of Medicine \\ and Pharmacy, 41 V. Babes, 400012 Cluj-Napoca, Romania; gavan.alexandru@umfcluj.ro (A.G.); \\ edinte@gmail.com (E.D.) \\ * Correspondence: oliviu_vostinaru@yahoo.com
}

\section{check for} updates

Citation: Tămaş, M.; Vostinaru, O.; Soran, L.; Lung, I.; Opris, O.; Toiu, A.; Gavan, A.; Dinte, E.; Mogosan, C. Antihyperuricemic,

Anti-Inflammatory and Antihypertensive Effect of a Dry Extract from Solidago virgaurea L. (Asteraceae). Sci. Pharm. 2021, 89, 27. https://doi.org/10.3390/

scipharm89020027

Academic Editor: Hermann Stuppner

Received: 30 April 2021

Accepted: 9 June 2021

Published: 14 June 2021

Publisher's Note: MDPI stays neutral with regard to jurisdictional claims in published maps and institutional affiliations.

Copyright: (c) 2021 by the authors. Licensee MDPI, Basel, Switzerland. This article is an open access article distributed under the terms and conditions of the Creative Commons Attribution (CC BY) license (https:// creativecommons.org/licenses/by/ $4.0 /)$.

\begin{abstract}
Solidago virgaurea L. is a perennial plant used in European traditional medicine as a diuretic or a remedy for inflammatory conditions of the urinary tract but also for gout, especially in the Balkans. The present study was focused on a preclinical, in vivo evaluation of antihyperuricemic, anti-inflammatory, and antihypertensive effects of a dry extract from S. virgaurea L. (ESV). Colorimetric and HPLC-MS techniques were used to identify the main chemical constituents of ESV. Antihyperuricemic effect of ESV was assessed in a rat model of hyperuricemia induced by the administration of potassium oxonate. Antihypertensive effect of ESV was evaluated in hyperuricemic rats by monitoring systolic blood pressure with a non-invasive blood-pressure recording system. The anti-inflammatory effect of ESV was tested using a rat model of paw edema. The main chemical constituents of ESV were rutin and phenolic acids represented by chlorogenic and caffeic acid. ESV demonstrated significant antihyperuricemic effects in rats due to an uricosuric mechanism. Additionally, ESV reduced the progression of arterial hypertension in hyperuricemic rats and also showed anti-inflammatory properties slightly inferior to diclofenac. The results suggest that ESV could be a natural remedy for the treatment of gout and protection against endothelial dysfunction caused by hyperuricemia.
\end{abstract}

Keywords: Solidago virgaurea L.; antihyperuricemic; anti-inflammatory; antihypertensive

\section{Introduction}

Gout is a metabolic disease usually affecting the joints, associated with severe pain and major impairment of quality of life [1]. Recent epidemiological data confirmed a global trend of increasing prevalence of gout with a constant increase in disability-adjusted life years from 1990 to 2017 [2]. The disease is caused by hyperuricemia which leads to crystallization, aggregation, and deposition of monosodium urate crystals in joints or soft tissues with a subsequent induction of a massive inflammatory response with leucocyte recruitment, local release of cytokines, reactive oxygen species and proteolytic enzymes [3]. Several studies identified other gout-associated comorbidities, such as arterial hypertension, chronic renal disease, or even diabetes and hyperlipemia, which may pose a significant threat to public health [4]. 
The modern pharmacological management of gout is generally aimed at the inhibition of uric acid formation using xanthine oxidase inhibitors, drugs such as allopurinol or febuxostat being considered the gold standards of therapy. The alternative approach of reducing hyperuricemia by increasing the urinary excretion of uric acid with uricosuric drugs was less explored, a limited number of molecules, such as probenecid or lesinurad, being available for gout therapy. In order to reduce occasional exacerbations (flares) of gout, patients must use, in addition to their hypouricemic treatments, either colchicine or non-steroidal anti-inflammatory drugs (NSAIDs) [5].

On the other hand, the therapeutical effects of the current gout medication are often associated with serious side effects, which may reduce patient compliance and ultimately the success of the treatment. In this context, the discovery of alternative drugs with antihyperuricemic properties could be important for large categories of patients; natural sources of new drugs are increasingly researched. Multiple studies have investigated the antihyperuricemic effect of natural products identifying several promising drug sources represented by plant species mainly from Asia: Smilax riparia, Sinofranchetia chinensis or Emblica officinalis [6,7]. In Europe, only few plant species, such as Taraxacum officinale, Populus nigra, or Betula pendula, were studied in relation to their antihyperuricemic effect [8,9]. Solidago virgaurea L. or goldenrod (Asteraceae) is a ubiquitous plant native to Europe, usually found from dry meadows to the forest edge. The plant has a height up to $1 \mathrm{~m}$ and numerous stalked golden yellow flowers arranged in a cluster at the top end of the stem [10]. S. virgaurea L. has been widely used in European traditional medicine as a diuretic or a remedy for inflammatory conditions of the urinary tract [11] but also in the treatment of gout, especially in the Balkan region [12]. Several experimental studies confirmed spasmolytic, diuretic, anti-inflammatory, and antimicrobial effects of S. virgaurea L. $[13,14]$, but the hypouricemic effect and its possible influence on blood pressure were not investigated. Thus, this work was focused on the preclinical evaluation of antihyperuricemic, anti-inflammatory, and antihypertensive effects of a dry extract from $S$. virgaurea (ESV).

\section{Materials and Methods}

\subsection{Reagents and Drugs}

Rutin and phenolic acids standards were obtained from Sigma-Aldrich (Taufkirchen, Germany). Acetonitrile and methanol (HPLC grade) were obtained from VWR Chemicals (Fontenay Sous Bois, France). Water was purified using a Milli-Q system (Millipore, Burlington, MA, USA).

Potassium oxonate, probenecid, and $\lambda$-carrageenan were purchased from SigmaAldrich (Taufkirchen, Germany). Diclofenac was purchased from Gerot Lannach Pharma (Wien, Austria).

\subsection{Plant material and Extract}

Aerial parts (herba) of $S$. virgaurea were harvested in the flowering period, from Ciucea (46 57'56" N 22 49'23" E), Cluj County, Romania, in 2019. After identification by an expert botanist, Dr. Gheorghe Coldea, a voucher specimen was deposited at the Institute for Biological Research in Cluj-Napoca, Romania. The dried and powdered vegetal material was extracted with $70 \%(v / v)$ ethanol at room temperature for $72 \mathrm{~h}$, with a yield of $350 \mathrm{mg} / \mathrm{g}$. Afterwards, it was concentrated and converted with adsorbing powders into a dry extract (ESV) in a fluid bed dryer (Strea Aeromatic, Bubendorf, Switzerland).

\subsection{Phytochemical Analysis}

The total flavonoid content (TFC) of $S$. virgaurea extract (ESV) was determined by the aluminum chloride colorimetric method [15], calculated, and expressed as rutin equivalents. The absorbance was measured at a wavelength of $430 \mathrm{~nm}$, using a JASCO V-530 (Jasco International Co., Ltd., Tokyo, Japan) UV-VIS spectrophotometer.

HPLC-MS analysis of flavonoids and phenolic acid components from ESV was performed using a previously described technique [16] with a LC2010 Shimadzu system (Shi- 
madzu, Kyoto, Japan), equipped with a photodiode array detector and a single quadrupole mass spectrometer. Chromatographic separation was performed on a LiChrosorb RP-18 column (Merck, Darmstadt, Germany). The elution was performed using the gradient mode with acetonitrile (A) and ultrapure water with $0.1 \%$ formic acid (B), at a flow rate of $0.43 \mathrm{~mL} / \mathrm{min}$. Identification of active compounds was performed by comparing retention times, UV spectra, and molecular mass of the peaks from the extract with those of the reference standards. The standard addition method was used for ESV components determination. The analyses were performed in triplicate for each sample.

\subsection{Animals}

Male Wistar rats (150-160 g) were purchased from the Practical Skills and Experimental Medicine Centre of Iuliu Haţieganu University, Cluj-Napoca, Romania. The animals were maintained on a $12 \mathrm{~h} \mathrm{light/dark} \mathrm{cycle} \mathrm{with} \mathrm{ad} \mathrm{libitum} \mathrm{access} \mathrm{to} \mathrm{food} \mathrm{and} \mathrm{water.} \mathrm{Study}$ design was approved by the Ethics Commission of the Iuliu Haţieganu University (decision no. 362/3 October 2019), Cluj-Napoca, Romania, being compliant with the EEC Directive 86/609, 1986.

\subsection{Antihyperuricemic Effect}

The antihyperuricemic effect of the dry ESV was evaluated by previously published methods $[17,18]$. Initially, all rats from the five groups included in the experiment $(n=6)$ were treated orally with $250 \mathrm{mg} / \mathrm{kg}$ potassium oxonate in order to block uricase and induce hyperuricemia. After $60 \mathrm{~min}$, control rats were administered saline solution by oral route and the animals from the reference group were treated orally with $125 \mathrm{mg} / \mathrm{kg}$ probenecid, a commercially available uricosuric agent. Additionally, the other three groups of rats were treated orally with 125,250 and $500 \mathrm{mg} / \mathrm{kg}$ ESV. After $24 \mathrm{~h}$ in metabolic cages, urine samples were individually collected, and blood samples were obtained from all rats included in the experiment by retroorbital sinus puncture under ketamine/xylazine anesthesia. Uric acid and creatinine were determined spectrophotometrically in the serum and urine, at $670 \mathrm{~nm}$, with a biochemistry analyzer (Vitros 250, Johnson and Johnson Clinical Diagnostic, New Brunswick, NJ, USA). A key parameter of uric acid handling, the fractional excretion of uric acid (FEUA) was calculated as [(urine urate $\times$ serum creatinine) /(serum urate $\times$ urine creatinine) $] \times 100$.

\subsection{Anti-Inflammatory Effect}

The anti-inflammatory effect of the dry ESV was tested in five rat groups $(n=6)$ using a previously published method $[19,20]$. Rats from the control group were treated orally with saline solution while the animals from the reference group received orally a dose of $20 \mathrm{mg} / \mathrm{kg}$ diclofenac. ESV was administered to three rat groups by oral route in doses of 125,250 , and $500 \mathrm{mg} / \mathrm{kg}, 60 \mathrm{~min}$ prior to a subplantar injection of $\lambda$-carrageenan $(1 \% \mathrm{w} / \mathrm{v}$, $0.1 \mathrm{~mL}$ ). The paw edema was evaluated with a digital plethysmometer (Ugo Basile, Varese, Italy) initially and at 1, 2, 3, and $4 \mathrm{~h}$ after the administration of $\lambda$-carrageenan. Edema was determined by subtracting the initial paw volume from the inflamed paw volume for all time intervals.

\subsection{Antihypertensive Effect in Hyperuricemic Animals}

The influence of hyperuricemia on systolic blood pressure and the possible antihypertensive effect the dry ESV were investigated using previously published methods [18,21]. Potassium oxonate in a dose of $250 \mathrm{mg} / \mathrm{kg}$ was administered orally to five groups of rats $(n=6)$, for 3 weeks, in order to induce hyperuricemia. Rats from the control group were treated with saline solution, while the animals from the reference group received, by oral route, for 3 weeks a dose of $125 \mathrm{mg} / \mathrm{kg}$ probenecid, a commercially available uricosuric agent. ESV was administered orally for 3 weeks to other three rat groups in doses of 125,250 , and $500 \mathrm{mg} / \mathrm{kg}$. Blood pressure was monitored weekly in all animals, with a non-invasive blood pressure recorder (Ugo Basile, Varese, Italy). 


\subsection{Statistical Analysis}

Statistical analysis was performed by one-way analysis of variance (ANOVA), followed by Dunnett test, with GraphPad Prism 6 software (GraphPad Software, San Diego, CA, USA). $p$ values $\leq 0.05$ were considered statistically significant.

\section{Results}

\subsection{Phytochemical Analysis}

The phytochemical analysis was focused on HPLC-MS quantification and identification of flavonoids and phenolic acids, considered to be the most important active compounds in Solidago species (Figure 1).

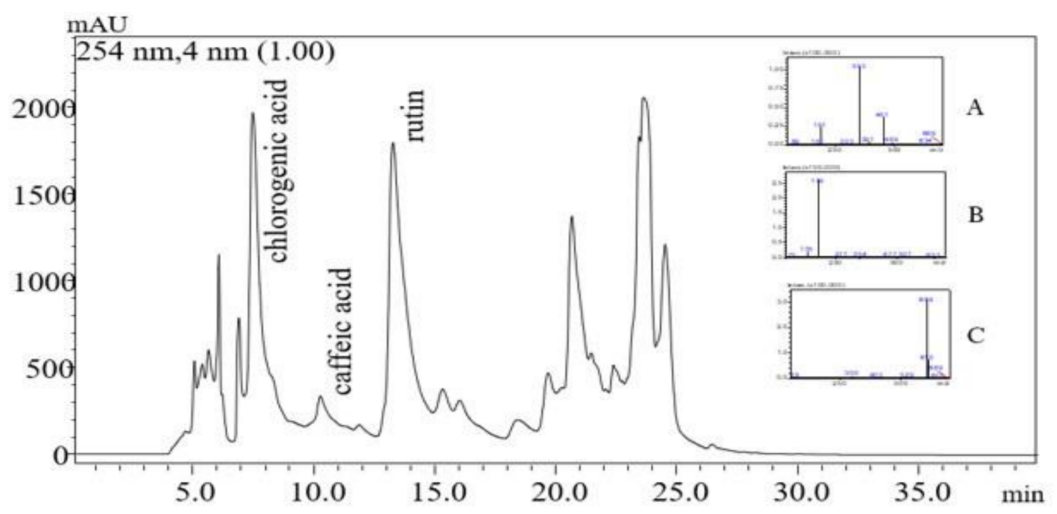

Figure 1. HPLC chromatogram of the extract from Solidago virgaurea L. and mass spectra of chlorogenic acid (A), caffeic acid (B), and rutin (C).

The HPLC-MS analysis showed a significant content of rutin $(2.041 \mathrm{mg} / \mathrm{g})$ and phenolic acids (chlorogenic acid, $3.708 \mathrm{mg} / \mathrm{g}$; and caffeic acid, $2.241 \mathrm{mg} / \mathrm{g}$ ) in the dry extract prepared from S. virgaurea (ESV). The total flavonoid content was $7.940 \mathrm{mg} / \mathrm{g}$, expressed as $\mathrm{mg}$ of rutin equivalents. These findings confirmed those of previously published studies reporting significant amounts of flavonoid compounds in the Solidago genus, which includes, in Romania, two adventive species (S. gigantea, S. canadensis) originating from North America, alongside the spontaneous species S. virgaurea. A recent study found a significant content of rutin and hyperoside in S. virgaurea, but also in S. gigantea and S. canadensis; therefore, due to the similarities in the chemical composition of the species from Solidago genus, morphoanatomical criteria could be used for a positive identification of S. virgaurea L. [22]. Although all three mentioned species of Solidago are rich in flavonoids, the therapeutical use of S. gigantea and S. canadensis could be limited by their high content of hemolytic saponins [23]. Other studies reported also the presence of additional molecules with promising biological potential, such as bis-desmosidic glycosides (leiocarposide and virgaureoside A) in the chemical composition of S. virgaurea [24].

\subsection{Antihyperuricemic Effect}

The oral administration of ESV in doses of 250 and $500 \mathrm{mg} / \mathrm{kg}$ caused a significant decrease of uricemia due to an augmented renal excretion of urate (Table 1). For the mentioned doses, the antihyperuricemic effect of ESV was superior to the reference uricosuric drug, probenecid. 
Table 1. Antihyperuricemic effect of the extract from S. virgaurea (ESV) in rats.

\begin{tabular}{cccccc}
\hline Group (Dose) & $\begin{array}{c}\text { Serum Uric Acid } \\
(\mathbf{m g} / \mathbf{d L})\end{array}$ & $\begin{array}{c}\text { Urine Uric Acid } \\
(\mathbf{m g} / \mathbf{d L})\end{array}$ & $\begin{array}{c}\text { Serum Creatinine } \\
(\mathbf{m g} / \mathbf{d L})\end{array}$ & $\begin{array}{c}\text { Urine Creatinine } \\
(\mathbf{m g} / \mathbf{d L})\end{array}$ & $\begin{array}{c}\text { Fractional Excretion } \\
\text { of Uric Acid }(\%)\end{array}$ \\
\hline $\begin{array}{c}\text { Oxonate control } \\
(250 \mathrm{mg} / \mathrm{kg})\end{array}$ & $1.30 \pm 0.20$ & $34.65 \pm 3.64$ & $0.72 \pm 0.03$ & $74.2 \pm 6.42$ & 25.86 \\
$\begin{array}{c}\mathrm{ESV} \\
(125 \mathrm{mg} / \mathrm{kg})\end{array}$ & $1.04 \pm 0.11$ & $72.80 \pm 3.70$ & $0.68 \pm 0.07$ & $107.3 \pm 4.98$ & 44.36 \\
$\begin{array}{c}\mathrm{ESV} \\
(250 \mathrm{mg} / \mathrm{kg})\end{array}$ & $0.86 \pm 0.08^{*}$ & $101.8 \pm 8.34^{*}$ & $0.53 \pm 0.04$ & $113.7 \pm 8.01$ & $55.17^{*}$ \\
$\begin{array}{c}\mathrm{ESV} \\
(500 \mathrm{mg} / \mathrm{kg})\end{array}$ & $0.60 \pm 0.07^{*}$ & $125.4 \pm 3.84^{*}$ & $0.48 \pm 0.05$ & $138.1 \pm 7.12$ & $72.64 *$ \\
$\begin{array}{c}\text { Probenecid } \\
(125 \mathrm{mg} / \mathrm{kg})\end{array}$ & $0.92 \pm 0.06^{*}$ & $54.67 \pm 4.32 *$ & $0.60 \pm 0.07$ & $89.5 \pm 8.03$ & 39.83 * \\
\hline
\end{tabular}

* Statistically significant, $p \leq 0.05$ vs. control; data are expressed as mean \pm SD.

The determination of uric acid and creatinine concentrations in the serum and urine facilitated the computation of an important parameter of uric acid turnover: fractional excretion of uric acid (FEUA), which is specifically increased by uricosuric drugs, such as probenecid or benzbromarone [25]. Thus, the reduced FEUA values $(25.86 \%)$ observed in hyperuricemic control rats, may indicate a significant reabsorption of uric acid at nephron level (Table 1). In this experimental model, the treatment with the highest dose of ESV caused a net augmentation of FEUA (72.64\%), suggesting that the antihyperuricemic effect may be explained by a uricosuric mechanism.

The antihyperuricemic effect of natural products was intensively researched, but most of the studies were focused on the inhibition of uric acid synthesis as a possible mechanism of action. Several investigations considered the assumption that flavonoids can reduce serum uric acid by inhibiting xanthine oxidase $(\mathrm{XO})$. A study proved that kaempferol could be inserted into the hydrophobic cavity of $X O$, blocking the enzyme [26]. Luteolin was also found to be a potent inhibitor of $\mathrm{XO}$ in vitro, with a $\mathrm{K}_{\mathrm{i}}$ of $2.38 \mathrm{~mol} / \mathrm{L}$ [27].

Our study identified the uricosuric effect as responsible for the antihyperuricemic properties of ESV. The molecular mechanisms of urinary uric acid excretion are still under investigation. A previously published study pointed out that the reduction of post-secretory reabsorption of sodium urate in the nephron could be a possible mechanism for the uricosuric effect [28]. Another study showed that rutin produced a significant antihyperuricemic effect in a mouse model of oxonate-induced hyperuricemia by downregulating the renal expression of mouse URAT1 transporter, the key structure involved in uric acid reabsorption in the kidneys [29].

Nonetheless, the complex pathophysiological processes linked to purine metabolism and the diversity of chemical composition of natural extracts may suggest that other mechanisms by which the tested ESV lowers uricemia and increases uricosuria are also possible.

\subsection{Anti-Inflammatory Effect}

The results of the assessment of anti-inflammatory effects of ESV in the experimental model of rodent paw edema test are presented in Table 2.

Table 2. Anti-inflammatory effect of the extract from S. virgaurea (ESV) in rat paw edema.

\begin{tabular}{cccccc}
\hline Group & Dose & Edema $\mathbf{~ h ~} \mathbf{( m L )}$ & Edema $\mathbf{~ h ~} \mathbf{( m L})$ & Edema $\mathbf{~ h ~}(\mathbf{m L})$ & Edema $\mathbf{~ h ~} \mathbf{( m L})$ \\
\hline Control (vehicle) & - & $0.72 \pm 0.09$ & $1.03 \pm 0.23$ & $2.28 \pm 0.41$ & $3.02 \pm 0.27$ \\
ESV & $125 \mathrm{mg} / \mathrm{kg}$ & $0.74 \pm 0.23$ & $1.10 \pm 0.48$ & $2.04 \pm 0.22$ & $2.89 \pm 0.36$ \\
ESV & $250 \mathrm{mg} / \mathrm{kg}$ & $0.70 \pm 0.14$ & $1.04 \pm 0.29$ & $1.87 \pm 0.58$ & $2.74 \pm 0.33$ \\
ESV & $500 \mathrm{mg} / \mathrm{kg}$ & $0.66 \pm 0.12^{*}$ & $0.81 \pm 0.14^{*}$ & $1.48 \pm 0.29^{*}$ & $1.38 \pm 0.26^{*}$ \\
Diclofenac & $20 \mathrm{mg} / \mathrm{kg}$ & $0.57 \pm 0.09^{*}$ & $0.73 \pm 0.21^{*}$ & $1.17 \pm 0.15^{*}$ & $1.30 \pm 0.26^{*}$ \\
\hline
\end{tabular}

* Statistically significant, $p \leq 0.05$ vs. control; data are expressed as mean \pm SD. 
Analysis of the data obtained for the highest dose of ESV $(500 \mathrm{mg} / \mathrm{kg})$ showed a statistically significant anti-inflammatory effect with a reduction of edema progression at all tested time points, the effects being marginally inferior to those of diclofenac, a reference non-steroidal anti-inflammatory agent. In the rat paw edema experimental model, the development of inflammatory process is caused initially by the liberation of multiple pro-inflammatory substances, such as histamine and serotonin, and later by an increased synthesis of eicosanoids in the affected tissue. The administration of ESV (500 mg/kg) inhibited both stages of inflammation, as seen in Table 2, with a significant reduction of inflammatory edema in the $1-2 \mathrm{~h}$ and $3-4 \mathrm{~h}$ time intervals.

Other investigations have been also focused on the anti-inflammatory effects of some of the main chemical constituents of ESV. The research of Yoo et al. demonstrated that rutin was able to reduce the inflammatory process caused by high mobility group box 1 (HMGB1) protein, a mediator involved in the final stages of severe vascular inflammation, the decrease of nuclear factor- $\mathrm{KB}$ and IL-6 synthesis being considered responsible for its anti-inflammatory effect [30]. Another study showed that flavonoids are able to exert an anti-inflammatory effect by decreasing the level of several factors, such as prostaglandins, cytokines, or intercellular adhesion molecules [31]. Additionally, the anti-inflammatory effects of chlorogenic acid, the main phenolic acid component from ESV, were confirmed by a previous study using in vivo experimental models, such as paw edema and formalin test in rodents [32].

Our data suggest that a reduction of synthesis and liberation of multiple pro-inflammatory mediators may contribute to the anti-inflammatory effect of ESV, but additional studies are necessary to elucidate its molecular mechanism.

\subsection{Antihypertensive Effect in Hyperuricemic Animals}

The results of the assessment of antihypertensive effect of ESV in hyperuricemic rats are presented in Table 3. The collected data showed a clear link between hyperuricemia and the increase of systolic blood pressure (SBP) in control oxonate-treated animals, visible especially in the third week of the experiment. The oral treatment with ESV prevented the development of arterial hypertension $(124.0 \pm 2.91 \mathrm{mmHg}$ at $500 \mathrm{mg} / \mathrm{kg}$ vs. $143.4 \pm 4.03 \mathrm{~mm}$ $\mathrm{Hg}$ in control rats), the effect of the highest dose being superior to the one of probenecid (Table 3).

Table 3. The antihypertensive effect of the extract from S. virgaurea (ESV) in hyperuricemic rats.

\begin{tabular}{|c|c|c|}
\hline Group (Dose) & $\begin{array}{c}\text { SBP Week } 0 \\
(\mathrm{~mm} \mathrm{Hg})\end{array}$ & $\begin{array}{c}\text { SBP Week } 3 \\
\text { (mm Hg) }\end{array}$ \\
\hline $\begin{array}{l}\text { Oxonate control } \\
(250 \mathrm{mg} / \mathrm{kg})\end{array}$ & $111.8 \pm 4.43$ & $143.4 \pm 4.03$ \\
\hline $\begin{array}{c}\text { Oxo + ESV } \\
(125 \mathrm{mg} / \mathrm{kg})\end{array}$ & $111.4 \pm 6.65$ & $138.2 \pm 6.18$ \\
\hline $\begin{array}{c}\text { Oxo + ESV } \\
(250 \mathrm{mg} / \mathrm{kg})\end{array}$ & $114.2 \pm 5.93$ & $134.8 \pm 4.76^{*}$ \\
\hline $\begin{array}{c}\text { Oxo + ESV } \\
(500 \mathrm{mg} / \mathrm{kg})\end{array}$ & $113.6 \pm 4.27$ & $124.0 \pm 2.91$ * \\
\hline $\begin{array}{l}\text { Oxo + Probenecid } \\
(125 \mathrm{mg} / \mathrm{kg})\end{array}$ & $113 \pm 4.30$ & $126.3 \pm 2.13$ * \\
\hline
\end{tabular}

The hypothesis that hyperuricemia is a risk factor for the development of arterial hypertension was tested by several researchers in preclinical or clinical settings. A previous study pointed out that a high level of serum uric acid may cause endothelial dysfunction and an elevated blood pressure due to a decrease of endothelial NO concentration in laboratory animals [33]. New research showed that uric acid could be produced directly inside endothelial cells by the enzyme xanthine oxidoreductase, with subsequent generation of re- 
active oxygen species, which could contribute to endothelial dysfunction [34]. The study of Agarwal et al., 2013, demonstrated, in humans, the correlation between hyperuricemia and arterial hypertension [35]. In Romania, a cross-sectional study, which enrolled 1920 adult patients, proved that the presence of hyperuricemia increased the odds of suboptimal blood pressure control and also induced a significantly lower glomerular filtration rate [36].

The influence of natural compounds on hyperuricemia and arterial hypertension was rarely investigated. A previous study tested antihypertensive effects of flavonoids, using different experimental models, and found that quercitin, the aglycon of rutin, showed antihypertensive effect in spontaneous hypertensive rats, L-NAME rats, DOCA-salt hypertensive rats, and metabolic syndrome rats [37].

Our findings confirmed the data from this study, showing that oral administration of ESV to hyperuricemic animals for 21 days decreased the progression of arterial hypertension. Furthermore, the coexistence of anti-inflammatory and antihypertensive effects for the tested ESV could provide an additional protection against endothelial dysfunction and subsequent cardiovascular impairment. New research is necessary to ascertain the therapeutic relevance of these findings.

\section{Conclusions}

This work reports for the first time an antihyperuricemic effect, based on a uricosuric mechanism, of a dry extract from S. virgaurea (ESV), in rats. Anti-inflammatory and antihypertensive effects of the same extract were also demonstrated in rats. The association of antihyperuricemic, anti-inflammatory, and antihypertensive effects of ESV may be valuable in the management of acute or chronic gout, providing an additional protection against endothelial dysfunction caused by hyperuricemia.

Author Contributions: Conceptualization, M.T. and O.V.; methodology, C.M.; software, A.G.; validation, M.T., O.V. and C.M.; formal analysis, E.D.; investigation, O.V., L.S., I.L., O.O., A.T., E.D., A.G.; resources, E.D.; data curation, O.V.; writing-original draft preparation, O.V.; writing-review and editing, O.V.; visualization, C.M.; supervision, C.M.; project administration, M.T.; funding acquisition, E.D. All authors have read and agreed to the published version of the manuscript.

Funding: This research received no external funding.

Institutional Review Board Statement: The study was conducted according to the guidelines of the Declaration of Helsinki and approved by the Ethics Committee of Iuliu Haţieganu University, Cluj-Napoca, Romania (protocol 362/3 October 2019).

Informed Consent Statement: Not applicable.

Data Availability Statement: All data presented or analyzed during this study are included in the article.

Acknowledgments: The authors would like to thank Gh. Coldea for his kind assistance.

Conflicts of Interest: The authors declare no conflict of interest.

\section{References}

1. Roddy, E.; Mallen, C.D.; Doherty, M. Gout. BMJ 2013, 347, f5648. [CrossRef] [PubMed]

2. Punzi, L.; Scanu, A.; Galozzi, P.; Luisetto, R.; Spinella, P.; Scire, C.A.; Oliviero, F. One year in review 2020: Gout. Clin. Exp. Rheumatol. 2020, 38, 807-821. [PubMed]

3. Pascual, E.; Addadi, L.; Andres, M.; Sivera, F. Mechanism of crystal formation in gout. Nat. Rev. Rheumatol. 2015, 11, 725-730. [CrossRef]

4. Feig, D.I. Serum uric acid and the risk of hypertension and chronic kidney disease. Curr. Opin. Rheumatol. 2014, 26, 176-185. [CrossRef] [PubMed]

5. Richette, P.; Garay, R. Novel drug discovery strategies for gout. Expert Opin. Drug Discov. 2013, 8, 183-189. [CrossRef] [PubMed]

6. Wu, X.H.; Wang, C.Z.; Wang, S.Q.; Mi, C.; He, Y.; Zhang, J.; Zhang, Y.W.; Anderson, S.; Yuan, C.S. Anti-hyperuricemia effects of allopurinol are improved by Smilax riparia, a traditional Chinese herbal medicine. J. Ethnopharmacol. 2015, 162, 362-368. [CrossRef]

7. Ling, X.; Bochu, W. A review of phytotherapy of gout: Perspective of new pharmacological treatments. Pharmazie 2014, 69, 243-256. [CrossRef] [PubMed]

8. Corp, N.; Pendry, B. The role of Western herbal medicine in the treatment of gout. J. Herb. Med. 2013, 3, 157-170. [CrossRef] 
9. Havlik, J.; Gonzalez de la Huebra, R.; Hejtmanikova, K.; Fernandez, J.; Simonova, J.; Melich, M.; Rada, V. Xanthine oxidase inhibitory properties of Czech medicinal plants. J. Ethnopharmacol. 2010, 132, 461-465. [CrossRef]

10. Wichtl, M.; Anton, R. Plantes Thérapeutiques, Tradition, Pratique Officinale, Science et Thérapeutique, 2nd ed.; EM Inter/Tec \& Doc: Paris, France, 2003.

11. European Medicines Agency (EMEA). Assessment Report on Solidago virgaurea L. Herba. 2008. Available online: https: / / www.ema.europa.eu/en/documents/herbal-report/assessment-report-solidago-virgaurea-1-herba_en.pdf. (accessed on 10 April 2021).

12. Menkovic, N.; Savikin, K.; Tasic, S.; Zdunic, G.; Stesevic, D.; Milosavljevic, S.; Vincek, D. Ethnobotanical study on traditional uses of wild medicinal plants in Prokletije mountains (Montenegro). J. Ethnopharmacol. 2011, 133, 97-107. [CrossRef]

13. Tămas, M. Solidago species in Phytotherapy. Acta Phytother. Rom. 2000, 6, 43-44.

14. El-Ghazaly, M.; Khayyal, M.T.; Okpanyi, S.N.; Arens-Corell, M. Study on the anti-inflammatory activity of Populus tremula, Solidago virgaurea and Fraxinus excelsior. Arzeim. Forsch. 1992, 42, 333-336.

15. Romanian Pharmacopoeia, 10th ed.; Editura Medicala: Bucuresti, Romania, 2015.

16. Plazonic, A.; Bucar, F.; Males, Z.; Mornar, A.; Nigovic, B.; Kujundzic, N. Identification and quantification of flavonoids and phenolic acids in Burr Parsley (Caucalis platycarpos L.) using high-performance liquid chromatography with diode array detection and electrospray ionization mass spectrometry. Molecules 2009, 14, 2466-2490. [CrossRef] [PubMed]

17. Sugino, H.; Shimada, H. Effect of isoproterenol on renal uric acid excretion in rats. Jpn. J. Pharmacol. 1987, 45, 343-348. [CrossRef]

18. Vostinaru, O.; Dinte, E.; Soran, M.L.; Lung, I.; Opris, O.; Mogosan, C. Evaluation of the anti-gout potential of an extract from Calluna vulgaris L. (Ericaceae) in rats. Rec. Nat. Prod. 2018, 12, 432-444. [CrossRef]

19. Winter, C.A.; Risley, E.A.; Nuss, G.W. Carrageenan-induced oedema in the hind paw of rat as an assay for anti-inflammatory activity. Proc. Soc. Exp. Biol. Med. 1962, 111, 544-547. [CrossRef] [PubMed]

20. Conea, S.; Mogosan, C.; Vostinaru, O.; Toma, C.C.; Cuc Hepcal, I.; Cazacu, I.; Pop, C.; Vlase, L. Polyphenolic profile, antiinflammatory and antinociceptive activity of an extract from Arctium lappa L. roots. Not. Bot. Horti Agrobot. 2017, 45, 59-64. [CrossRef]

21. Mazzali, M.; Hughes, J.; Kim, Y.G.; Jefferson, A.; Kang, D.H.; Gordon, K.L.; Lan, H.Y.; Kivlighn, S.; Johnson, R. Elevated uric acid increases blood pressure in the rat by a novel crystal-independent mechanism. Hypertension 2001, 38, 1101-1106. [CrossRef] [PubMed]

22. Dobjanschi, L.; Paltinean, R.; Vlase, L.; Babota, M.; Fritea, L.; Tamas, M. Comparative phytochemical research of Solidago genus: S. graminifolia. Note I. Flavonoids. Acta Biol. Marisiensis 2018, 1, 18-26. [CrossRef]

23. Tămaș, M.; Roșca, M. Cercetări asupra saponinelor din speciile indigene de Solidago. Farmacia 1988, 36, 167-172.

24. Hiller, K.; Fötsch, G. Zur quantitativen Verteilung der Phenolglykoside Virgaureosid A und Leiocarposid in Solidago virgaurea L. Pharmazie 1986, 41, 415-416.

25. Narang, R.K.; Vincent, Z.; Phipps-Green, A.; Stamp, L.K.; Merriman, T.R.; Dalbeth, N. Population-specific factors associated with fractional excretion of uric acid. Arthritis Res. Ther. 2019, 21, 234. [CrossRef] [PubMed]

26. Wang, Y.; Zhang, G.; Pan, J.; Gong, D. Novel insights into the inhibitory mechanism of kaempferol on xanthine oxidase. J. Agric. Food Chem. 2015, 63, 526-534. [CrossRef] [PubMed]

27. Yan, J.; Zhang, G.; Hu, Y.; Ma, Y. Effect of luteolin on xanthine oxidase: Inhibition kinetics and interaction mechanism merging with docking simulation. Food Chem. 2013, 141, 3766-3773. [CrossRef]

28. Sugino, H.; Shimada, H. The uricosuric effect in rats of E5050, a new derivative of ethanolamine involves inhibition of the tubular postsecretory reabsorption of urate. Jpn. J. Pharmacol. 1995, 68, 297-303. [CrossRef]

29. Chen, Y.-S.; Hu, Q.-H.; Zhang, X.; Zhu, Q.; Kong, L.-D. Beneficial effect of rutin on oxonate-induced hyperuricemia. Pharmacology 2013, 92, 75-83. [CrossRef]

30. Yoo, H.; Ku, S.-K.; Baek, Y.-D.; Bae, J.-S. Anti-inflammatory effects of rutin on HMGB1-induced inflammatory responses in vitro and in vivo. Inflamm. Res. 2014, 63, 197-206. [CrossRef]

31. Serafini, M.; Peluso, I.; Raguzzini, A. Flavonoids as anti-inflammatory agents. Proc. Nutr. Soc. 2010, 69, 273-278. [CrossRef]

32. Dos Santos, M.D.; Almeida, M.C.; Lopes, N.P.; De Souza, G.E. Evaluation of the anti-inflammatory, analgesic and antipyretic activities of the natural polyphenol chlorogenic acid. Biol. Pharm. Bull. 2006, 29, 2236-2240. [CrossRef]

33. Khosla, U.M.; Zharikov, S.; Finch, J.L.; Nakagawa, T.; Roncal, C.; Mu, W.; Krotova, K.; Block, E.R.; Prabhakar, S.; Johnson, R.J. Hyperuricemia induces endothelial dysfunction. Kidney Int. 2005, 67, 1739-1742. [CrossRef]

34. Scheepers, L.E.J.M.; Wei, F.-F.; Stolarz-Skrzypek, K.; Malyutina, S.; Tikhonoff, V.; Thijs, L.; Salvi, E. Xanthine oxidase gene variants and their association with blood pressure and incident hypertension: A populational study. J. Hypertens. 2016, 34, $2147-2154$. [CrossRef]

35. Agarwal, V.; Nidhi, H.; Messerli, F.H. Effect of alopurinol on blood pressure: A systematic review and meta-analysis. J. Clin. Hypertens. 2013, 15, 435-442. [CrossRef]

36. Buzas, R.; Tautu, O.-F.; Dorobantu, M.; Ivan, V.; Lighezan, D. Serum uric acid and arterial hypertension-data from Sephar III survey. PLoS ONE 2018, 13, e0199865. [CrossRef]

37. Perez-Vizcaino, F.; Duarte, J.; Jimenez, R.; Santos-Buelga, C.; Osuna, A. Antihypertensive effects of the flavonoid quercetin. Pharmacol. Rep. 2009, 61, 67-75. [CrossRef] 